\title{
A Study on Nursing Students' Subjectivity of the Disabled
}

\author{
Sunyoung Jang ${ }^{1}$ \\ ${ }^{I}$ Associate Professor, Department of Nursing, Hanseo University, South Korea, sjang@hanseo.ac.kr
}

\begin{abstract}
The objectives of this study are to understand the subjectivity of the disabled perceived by nursing students, to describe its characteristics in each type, and to understand the categorization of the disabled, by applying the Q-methodology. A total 15 th year nursing students who carried out practice in A university, were asked to classify 38 statements. The collected data was analyzed by using the QUANL PC Program. In the results of this study, the nursing students' perception of the disabled was divided into two factors such as 'social/policy-level support highlighted type' and 'guardian support highlighted type'. In the results of analyzing the subjectivity of the disabled by using the PC QUANL program, there were total two factors, explaining $51.86 \%$ of total variance. The factor 1 was $40.25 \%$ while the factor 2 was $11.61 \%$. Among total 15 research subjects, ten people belonged to the factor 1 , and the rest five people belonged to the factor 2 . This study on the subjectivity would be helpful for changing the perception of the disabled in our society. Moreover, it could be utilized as the basic data for the development of differentiated educational programs, by presenting the subjectivity structure and characteristics of each type of perception of the disabled targeting the nursing students as preservice medical personnel.
\end{abstract}

Keywords: The Disabled, Nursing Student, Subjectivity, Q-Methodology, Nurses

\section{Introduction}

In modern society, due to the industrialization and mechanization caused by complex and diverse environmental elements, the probability of exposing to all sorts of unexpected accidents and diseases is increasing. Thus, the risk to get disabilities is increasing. In case of Korea, the number of the disabled registered each year is gradually increasing, and the percentage of the disabled in the total population was increased from $2.0 \%(\mathrm{~N}=1,449,496)$ in 2000 to $2.6 \%(\mathrm{~N}=2,490,406)$ in 2015[1]. Even though the disabled population is increasing and the perception or attitude towards the disabled is socially emphasized, the social perception of the disabled is negative and they are treated as people with low social status by regarding physical disabilities as emotional and psychological problems, or beings different from healthy people[2]. The attitude towards the disabled has been negative for thousands of years, and they have been alienated and socially discriminated more severely than homosexuals or foreign workers. In Korea, the researches on the attitude or perception of the disabled were started from the early 1980s, and the measures for improving the problems of the disabled are performed. Even though the problems of the disabled were solved compared to the past through practices such as improvement in the legal/physical aspect and enhancement of perception, for the true integration with the disabled, there should be changes in ordinary people's perception through their psychological and social approaches to the disabled[3].

One of the procedures for changing the perception is to make contact between the disabled and nondisabled. According to a preceding research, the people who have experiences in contacting with the

Received: April 13, 2021; $1^{\text {st }}$ Review Result: May 31, 2021; $2^{\text {nd }}$ Review Result: July 19, 2021

Accepted: August 30, 2021 
disabled tend to have more favorable attitude towards them than people who have no experiences[4]. However, the experience in contacting with the disabled does not always positively change the perception and attitude towards the disabled, and the simple experience in contacting with the disabled could cause more negative attitude towards them. As the most important method to change the perception through contact with the disabled, when the contact is direct and structuralized, the perception of the disabled is changed more favorably[4].

As the people who will be dealing with the issues of the disabled in the future, the university students' attitude towards the disabled would form the fundamental basis of social atmosphere such as welfare for the disabled in the future. Moreover, as medical personnel in the future, the nursing students' attitude towards the disabled could influence not only the health environment, but also the overall society, so the nursing students' positive attitude towards the disabled is important. Most of the preceding researches on the perception and attitude towards the disabled are no more than researches on the actual status[5, $6]$.

As the core manpower who makes the most contact with patients in health medical site, the nurses should provide the safe and high-quality nursing to patients within limited time in the rapidly-changing health medical environment[7]. When dealing with patients in nursing site, the subjectivity of perception has much influence on their nursing. Thus, it is important to understand the perception by nurses and preservice nurses. As a methodology based on performer's perspective instead of researcher's hypotheses, the Q-methodology could understand the characteristics of each type according to human's subjectivity structure[8]. The nursing students' perception of the disabled is the subjects' subjective and unique experience, so the Q-methodology considering the subjectivity of subjects is a proper research method to verify the nursing students' perception type of the disabled.

Thus, this study is aimed to provide basic data necessary for developing the differentiated educational programs according to the characteristics of preservice nurses' perception of the disabled, by understanding the subjectivity structure of the disabled in the perspective of nursing students.

The objectives of this study are to provide information about nursing students dealing with patients with disabilities, and also to provide the basic data for presenting strategies to educate nursing students, by examining the types of subjective perception of the disabled and the characteristics of each type targeting the nursing students, with the application of Q-methodology. The concrete research objectives are as follows.

1) The nursing students' subjective perception of the disabled is categorized.

2) The characteristics of each type of nursing students' perception of the disabled are analyzed and described.

\section{Research Methods}

\subsection{Research Design}

To achieve the objectives of this study, after considering the literature, media data, and preceding researches on the disabled, it is aimed to examine the subjectivity showing the types of subjective perception of the nursing students towards the disabled individuals.

\subsection{Selection of Q-Population and Q-Sample}

In order to extract the comprehensive statements on the effects of the disabled targeting the current nursing students, the Q-population was drawn through the consideration of domestic/foreign-relevant literature, open-ended questionnaire, and individual in-depth interview. In this process, the Q-population with about 200 samples was drawn. Besides it, the Q-population with total 100 samples were extracted 
by integrating the collected literature through the consideration of domestic/foreign-relevant literature. After reviewing and modifying the extracted Q-samples, this study finally selected total 38 samples with high discrimination.

\subsection{Selection Method of P-Sample}

As a qualitative research method emphasizing individuals' inertia by focusing on not interindividual differences, but intraindividual differences of significance or importance, the Q-methodology is based on the small sample doctrine in which the characteristics are not clearly shown when the P-sample gets big and many people are concentrated in a factor[8]. As the P-sample, this study selected total 15 nursing students who voluntarily agreed on the participation in this study after fully explaining the objectives of this study to them.

\subsection{Q-Classification and Data Analysis Method}

The Q-classification is a process in which each research subject selected as P-sample makes the voluntary definition of the disabled by classifying the statements of Q-sample in the forced normal distribution method[9]. The data was collected by using Q-cards, targeting total 15 nursing students of OO university. It took about 30-45 minutes for each research subject to complete the Q-classification. In the distribution of Q-sample, the research subjects classified the statements selected as Q-sample from strong affirmation to strong negation according to the importance based on their own opinions. The statement $(\mathrm{Q} 1)$ about the disabled was classified in the 12-point scale. After that, in relation to the statements classified into both extremes, the further interview with subjects was conducted. For the Qfactor analysis, the Principle Component Factor Analysis(varimax) method was used. The classification of types was selected by considering the total variance explained and results produced by variously inputting the number of factors based on the Eigen value 1.0 or up. Regarding the collected data, the transformed scores(1-12 points) given to the forcedly-distributed card of Q-sample distribution table were scored. Coding the given transformed scores in the order of Q-sample No., it was processed with the Principle Component Factor Analysis by the QUANL PC Program. For the data analysis, the QUANL pc program was used[10-12].

\subsection{Ethical Consideration of Research Subjects}

After asking the subjects for voluntary consent before starting the research, they were informed that they could stop participating anytime. To respect the subjects' rights, and to guarantee privacy and confidentiality, all the collected data was anonymously processed, coded, and Q-sorted in the whole processes of data analysis.

\section{Results}

To analyze the nursing students' subjectivity of the disabled in each type, first, the characteristics of each type were described focusing on the statements of each type. The Q-responses of Psamples(research participants) were divided into upper items and lower items, and then total three factors were extracted. In the Q-methodology, among the people belonging to each type, the person with high factor weight is the typical or ideal person representing the type.

This study mainly interpreted the meanings of statements with z-score as \pm 1.00 or up among the items of classified statements to analyze the characteristics of each type of the disabled. In this study, there were ten people with factor weight as 1.0 or up in Type 1, and five people in Type 2 . 
In the results of analyzing the subjectivity of the disabled by using the PC QUANL program, there were total two factors, explaining $51.86 \%$ of total variance. The factor 1 was $40.25 \%$ while the factor 2 was $11.61 \%$. As the factor 1 has the $40.25 \%$ explanatory power, it could be regarded as a factor explaining the most of the disabled[Table 1]. Among total 15 research subjects, ten people belonged to the factor 1 , and the rest five people belonged to the factor 2 . The people belonging to each factor mean a group showing similar responses to the disabled.

[Table 1] Eigen Value, Variance, and Cumulative Percentage

\begin{tabular}{|c|c|c|}
\hline & Type I & Type II \\
\hline Eigen Value & 6.0371 & 1.7419 \\
\hline Variance(\%) & .4025 & .1161 \\
\hline Cumulative( \% ) & .4025 & .5186 \\
\hline
\end{tabular}

The correlation coefficients between the three factors are shown in [Table 2]. This shows the degree of similarity between the two types. The correlation coefficient between type 1 and type 2 is 0.335 . However, the correlation between factors in the Q method is different from the factor analysis method in the quantitative research, and since it focuses on finding the factors without presupposing the complete independence between the factors, there is no controversy over the method of factor extraction based on the high and low correlation.

[Table 2] Correlations Between Factor Scores

\begin{tabular}{|c|c|c|}
\hline Hospitals & Type I & Type II \\
\hline Type I & 1.000 & .335 \\
\hline Type II & - & 1.000 \\
\hline
\end{tabular}

The types of subjectivity of the disabled produced by this type analysis method could be presented as follows.

- Social/Policy-Level Support Highlighted Type: The Type 1 included total ten subjects. The subjects of Type 1 showed strong affirmation in the statements such as 'The lifelong education center should be established for the disabled. $(\mathrm{Z}=1.62)$ ', 'The guardian is worried about the future of the disabled as he/she becomes senescent.( $Z=1.60)$ ', and 'The different education in each age should be provided to the disabled based on human's development stage. $(Z=1.52)$ ' [Table 3]. The subject with the highest factor weight in Type 1 was No. 5(6.5586), and the statements with the strongest affirmation were No. 1 and No. 30. The statements with strong negation by the subjects of Type 1 were 'The physical disabilities are preventable. $(\mathrm{Z}=-2.04)$ ', 'The physical disabilities are preventable. $(\mathrm{Z}=-1.46)$ ', and 'It is more effective for children with disabilities to get educated in general school than special school. $(Z=-$ 1.35)'[Table 3]. The subject with the lowest factor weight in Type 1 was No. 15(0.3695), and the statements with the strongest negation were No. 24 and No. 18.

In the characteristics of Type 1, they thought that there should be some efforts to support self-reliance and independent life of the disabled according to the numerical increase of the disabled. They regarded it not as individual efforts from parents or guardians, but as an issue that should be solved by our society, so everyone should make efforts to establish the measures together. According to them, it would be necessary to provide helpful support to the disabled such as lifelong education center, differentiated 
education, and job development for the disabled, and also the state and local governments should establish the long-term policies. Therefore, the Type 1 was named 'social/policy-level support highlighted type'.

- Guardian Support Highlighted Type: The Type 2 included total five subjects. The subjects of Type 2 showed strong affirmation in the statements such as 'The guardian is worried about the future of the disabled as he/she becomes senescent. $(\mathrm{Z}=2.51)$ ', 'The siblings of the disabled always feel pressured to concede. $(Z=2.13)$ ', and 'For the rearing of the disabled, it is tough for their guardians to do economic activities. $(Z=2.05)$ ' [Table 3]. The subject with the highest factor weight in Type 2 was No. 6(1.5833), and the statements with the strongest affirmation were No. 30 and No. 31. The statements with strong negation by the subjects of Type 2 were 'The autistic children should get help from their parents in their lifetime. $(\mathrm{Z}=-2.02)$ ', 'The guardians of the disabled more actively participate in religious activities. $(\mathrm{Z}=-$ 1.72)', and 'It is more effective for children with disabilities to get educated in general school than special school.( $Z=--1.65)^{\prime}$ [Table 3]. The subject with the lowest factor weight in Type 2 was No. 12(0.8069), and the statements with the strongest negation were No. 7 and No. 32 .

In the characteristics of Type 2, they think that it is important to support the guardians of the disabled as the care or support of the disabled is still mainly handled by their families in Korean society. Especially, the parents of the disabled are worried about the future of their disabled children after their death. And due to the continuous care, sometimes, it is impossible to have daily life. Thus, they said that the siblings of the disabled would always live their lives for the sake of disabled siblings as their parents would also do so. However, the children without disabilities could also experience psychological wound or loss because of this, so it would be also necessary to support them. Every family member including a person with disabilities has different burden or experience, and difficulties in their own position, so there should be social consideration or programs for them. Therefore, the Type 2 was named 'guardian support highlighted type'.

[Table 3] Representative Items and Z-score of the Disabled

\begin{tabular}{|c|c|c|c|c|c|}
\hline \multicolumn{6}{|c|}{ Representative items of type } \\
\hline Factor & Type & No & Representative items & Mean(SD) & Z-score \\
\hline \multirow{10}{*}{$\begin{array}{c}\text { Type1 } \\
(\mathrm{N}=10)\end{array}$} & \multirow{5}{*}{ Factorl } & 1 & The lifelong education center should be established for the disabled. & $8.60(1.838)$ & 1.62 \\
\hline & & 30 & $\begin{array}{l}\text { The guardian is worried about the future of the disabled as he/she } \\
\text { becomes senescent. }\end{array}$ & $9.10(2.644)$ & 1.60 \\
\hline & & 2 & $\begin{array}{l}\text { The different education in each age should be provided to the } \\
\text { disabled based on human's development stage. }\end{array}$ & $8.50(1.179)$ & 1.52 \\
\hline & & 26 & $\begin{array}{l}\text { The state and local government should seek for the policies } \\
\text { necessary for complementing the disabilities }\end{array}$ & $8.30(1.636)$ & 1.40 \\
\hline & & 5 & The 4th industrial society should develop the jobs for the disabled. & $8.10(1.729)$ & 1.19 \\
\hline & \multirow{5}{*}{ Factor 2} & 24 & The physical disabilities are preventable. & $2.30(1.567)$ & -2.04 \\
\hline & & 18 & The environmental pollution increases the number of the disabled. & $3.30(1.252)$ & -1.46 \\
\hline & & 6 & $\begin{array}{l}\text { It is more effective for children with disabilities to get educated in } \\
\text { general school than special school. }\end{array}$ & $3.00(1.155)$ & -1.35 \\
\hline & & 34 & $\begin{array}{l}\text { For the rearing of the disabled, it is tough for their guardians to do } \\
\text { economic activities. }\end{array}$ & $5.30(3.057)$ & -1.30 \\
\hline & & 27 & It is hard to meet the physiological/physical desires of the disabled. & $3.00(1.764)$ & -1.24 \\
\hline $\begin{array}{l}\text { Type2 } \\
(\mathrm{N}=5)\end{array}$ & Factor 3 & 30 & $\begin{array}{l}\text { The guardian is worried about the future of the disabled as he/she } \\
\text { becomes senescent. }\end{array}$ & $10.60(0.548)$ & 2.51 \\
\hline
\end{tabular}




\begin{tabular}{|c|c|c|c|c|}
\hline & 31 & The siblings of the disabled always feel pressured to concede. & $10.00(1.000)$ & 2.13 \\
\hline & 34 & $\begin{array}{l}\text { For the rearing of the disabled, it is tough for their guardians to do } \\
\text { economic activities. }\end{array}$ & $9.80(1.789)$ & 2.05 \\
\hline & 22 & $\begin{array}{l}\text { To develop services for the disabled, it would be necessary to } \\
\text { communicate with their supporters. }\end{array}$ & $8.00(1.732)$ & 1.09 \\
\hline & 19 & $\begin{array}{l}\text { If diseases and wounds are quickly treated, the people with acquired } \\
\text { disabilities could be reduced. }\end{array}$ & $7.80(2.049)$ & 1.06 \\
\hline \multirow{5}{*}{ Factor 4} & 7 & $\begin{array}{l}\text { The autistic children should get help from their parents in their } \\
\text { lifetime. }\end{array}$ & $2.20(1.304)$ & -2.02 \\
\hline & 32 & $\begin{array}{l}\text { The guardians of the disabled more actively participate in religious } \\
\text { activities. }\end{array}$ & $3.00(2.345)$ & -1.72 \\
\hline & 6 & $\begin{array}{l}\text { It is more effective for children with disabilities to get educated in } \\
\text { general school than special school. }\end{array}$ & $2.80(1.643)$ & -1.65 \\
\hline & 18 & The environmental pollution increases the number of the disabled. & $4.20(1.789)$ & -1.16 \\
\hline & 12 & $\begin{array}{l}\text { The aged pregnant women are highly possible to give birth to a } \\
\text { child with disabilities. }\end{array}$ & $4.40(2.408)$ & -1.08 \\
\hline
\end{tabular}

\section{Discussions}

In the results of this study, the types of subjectivity of the disabled perceived by nursing students were divided into Type 1 - 'social/policy-level support highlighted type' and Type 2 - 'guardian support highlighted type', and this study aims to discuss the characteristics of each type.

In this study, the Type 1 was 'social/policy-level support highlighted type'. If the disabled population is regarded to be continuously increasing, there should be varied supports for them, they thought. Instead of regarding the care of the disabled just as their family's duty in the past, it would be necessary to seek for social and policy-level alternatives, so the disabled could become independent. Through the measures, the government and community should help the disabled to be able to fully work as a member of society based on the community spirit.

On top of the disabled by inborn causes, the number of the disabled by acquired causes like accident or disease is also continuously increasing. Thus, everyone without disabilities has the possibility to become the disabled in the future. Once the range of disability is expanded, the number of the registered disabled would be increasing to the level of advanced countries, so it would be necessary to provide more efficient healthcare and rehabilitation to the disabled. For more efficient healthcare and rehabilitation of the disabled, it would be needed to create an atmosphere in which every member of society has positive attitude towards the disabled, and the disabled could initiatively and actively participate in their rehabilitation[13].

Also, the state should increase the awareness of policies related to disability, reflecting the needs of the disabled, through active promotional activities of policies and welfare services for the disabled. It would be necessary to raise the awareness of welfare service for the disabled, and also to eventually increase the service benefits, by regularly notifying the types of welfare service for the disabled and how to use them through Rehabilitation International Korea or community rehabilitation centers for the disabled. Once the ordinary people's awareness of disability policy is improved, their attitude towards the disabled could be changed, so there should be strategies to promote disability policy and welfare service to ordinary people[14].

In the results of surveying the priority of disability policy, all the medical personnel, ordinary people, and the disabled regarded the medical security, income security, and expansion of amenities as the disability welfare service that should be the most preferentially performed. The ordinary people and 
medical personnel also regarded the improvement of perception of the disabled and expansion of employment support service for them as important while the disabled regarded the housing security and housework support service as important[15]. This result was similar to the research by Lee \& $\operatorname{Kim}(2004)$ surveying the preferential needs of the disabled from society or state, and reporting the high needs of income security, medical security, and housing security. To increase the efficiency of disability policy or welfare service, the needs of the disabled as beneficiaries of service should be actively reflected [16]. Most of all, the medical personnel who are primarily responsible for the development of disability policy and provision of disability welfare service should make efforts to collect opinions through regular communications with the disabled and ordinary people for developing disability policy and disability welfare service reflecting the needs of the disabled.

Our society needs the consistent social support policy that supports for the self-reliance of adults with disabilities in community. For this, there should be social resources and alternatives such as public care support, housing, job, lifelong education, and healthcare that could be selected by adults with disabilities. On top of social perception in which it is so natural for the disabled to choose to live in community after getting out of their families, the support system for this should be extensively constructed. In fact, it would be meaningful to provide the psychological/emotional support to exhausted families of the disabled when establishing the social support system for the self-reliance of adults with disabilities.

The Type 2 was 'guardian support highlighted type'. Our society is still expecting that a lot of care and support of the disabled are handled by their families from their birth to death. Thus, in case of this type, they think that not only the disabled, but also their families should be socially protected and supported in policy-level. Their burden or sacrifice should not be regarded as natural.

The disability causes the biggest influences and changes in the disabled, and it also has influences on their families[17]. The influences of disability on families could be varied like economic hardship caused by disability, parenting stress by rearing a child with disabilities, and family's acceptance and adaptation to a family member with acquired disability such as stroke.

Based on the perception of care within family as economic benefits in the background of socialization of care, the size of its value is sometimes estimated. Actually, when the Australian government conducted a survey on family care in 2003, it estimated that about $13 \%$ of Australian population were taking care of family members such as the disabled, elderly, and children, and 1/5 of them were main caregivers. Considering the family care as social contribution, the economic value was estimated as 4.9billion dollars(total amount of income that could be earned in case when a family caregiver works) and 30.5billion dollars(total amount of cost in case when the paid-care is selected instead of family care)[17].

There is a need to pay attention to the burden of care because it reduces the physical/psychological health of family caregivers; it could cause the reduction of their social activities; and the psychological/mental health of family caregivers could have influences on the proper care support of the disabled again. Especially, the depression of family members who continuously feel the burden of care for the disabled and elderly, has been researched as a risk factor of suicidal ideation/attempt[18]. Considering that the suicidal ideation is a strong predicting variable of suicidal attempt, it is needed to pay attention to the depression as an intervention point to prevent more extreme results.

Even though the family caregivers are providing care to the disabled such as support of daily life, and also experiencing difficulties like low level of mental/psychological health, they are not perceived as the recipients of welfare policy support for the disabled. Even when they get support, there are limitations of disability type or age of the disabled, so it is rare to find the support focusing on the families of the disabled[19].

As the unbalanced state of actual or perceived needs and abilities in family function, the family stress could be the tension and pressure within the family system, which is unavoidably experienced in the process when a family and each member are developing and changing as time passes [19]. Most families 
of the disabled face difficult situations that cannot be handled by their own abilities, so they not only experience psychological/emotional confusions, but also get threatened to their physical/psychological health. Thus, their stress caused by the state of chronic tension is greater compared to ordinary families. Thus, in order for the families with the disabled to successfully adapt themselves to continuous internal needs and stimuli, their physical and psychological health would be very important.

The healthy family means a family that could form a positive family identity, enhance satisfactory and sufficient interactions between family members, promote the development of every member and group of family, and also cope with stresses[20]. Especially, the families with the disabled have the higher degree of stress than ordinary families, so it would be necessary to manage the stress of families with the disabled.

The problems of family members should be understood not in the individual level, but in the whole context of family. Based on this perspective, according to the principles of family support by Dunst, Trivette, \& Deal(1994) in the 'guidelines for successful family support program' presented by the Family Support America of the United States, the provision of various services to families could strengthen the strengths of families, and it would be the most important to sensitively respond to families' needs. In other words, it should be based on the philosophy of Family Empowerment in which the families with the disabled could perceive that they could solve their own problems, by helping the family members to use official/unofficial resources based on their needs and strengths[20].

This study explored the nursing students' subjective perception of the disabled, and then analyzed it by dividing it into two types. Through this study, first, it would be necessary to change the basic perception of the disabled, their families, and policy. Such changes would be helpful to overcome the physical/psychological prejudices against the disabled, which would be led to the social return of patients with disabilities. In the characteristics of each type, there were 'social/policy-level support highlighted type' regarding the introduction of national/social policy and institution related to the disabled as the priority, and 'guardian support highlighted type' thinking that it would be necessary to support the guardians and families who provide psychological/financial care to the disabled.

This study on the subjectivity would be helpful in changing the perception of the disabled in our society. Moreover, it could be utilized as the basic data for the development of differentiated educational programs, by presenting the subjectivity structure and characteristics of each type of perception of the disabled targeting the nursing students as preservice medical personnel.

However, this study only targeted a university and did not consider the factors having influences on the perception of the disabled when selecting the subjects, so the results of this study are limited to be generalized. Thus, there should be additional verification by follow-up researches on the types by composing the Q-sample with diverse backgrounds.

\section{Conclusions}

This study is aimed to establish the basic data necessary for presenting the change of perception of the disabled and the approach nursing students' subjective perception of the disabled, by applying the Q-methodology. In the results of this study, it was divided into two factors. The types of the disabled perceived by nursing students were 'social/policy-level support highlighted type' and 'guardian support highlighted type'.

This study is intended to provide the basic data for establishing the measures for improving the attitude and perception of the disabled in the future, by categorizing the nursing students' subjectivity of the disabled. As this study analyzed the nursing students' perception of the disabled and also verified the characteristics of each type, it should be led to the development of educational programs considering the characteristics of each type. This study also suggests an additional research on type analysis by 
extracting samples after considering various factors, and a qualitative research for verifying diverse factors having influences on the nursing of patients with disabilities.

\section{References}

[1] http://kosis.kr/wnsearch/totalSearch.jsp, Sept 30 (2016)

[2] Disability Rights Institute, 2013 Improving awareness of the disabled and prohibiting discrimination, http://15775364.or.kr/bbs/board.php?bo_table=B61\&wr_id=1, Jul 28 (2013)

[3] Y. F. Lee, A study on factors influencing on attitude to accommodate the disabled by university students, Yonsei University, Master's Thesis, (2015)

[4] J. H. Choi, The effects of volunteer and mass media to University students`attitude toward the disabled, Yonsei University, Master's Thesis, (2008)

[5] S. H. Son, The characteristics of the social distance of children from disabled classmates in inclusive Ccass, The Journal of Special Children Education, (2005), Vol.7, No.4, pp.147-170.

[6] J. H. Yang, Effects on mainstreaming of circle activities about disabilities: preservice early childhood teachers attitude, efficacy, and performance, Korean Journal of Child Studies, (2007), Vol.28, No.1, pp.147-170.

[7] S. Dyess, C. Parker, Transition support for the newly licensed nurse: a programme that made a difference, Journal of Nursing Management, (2012), Vol.20, No.5, pp.615-623.

[8] M. Wang, S. Jang, Study of Subjectivity on Well-dying in Nursing Students, Asia-pacific Journal of Psychology and Counseling, (2018), Vol.2, No.2, pp.159-164.

[9] S. M. Whang, S. W. You, J. Y. Kim, R. G. Kim, Q Methodology and Theory : Consumer Types and Cultural Consumption Characteristics of Korean Society: Who Spends for What Reasons?, Journal of Korean Society for the Scientific Study of Subjectivity, (2006), Vol.13, pp.25-39, https://kiss.kstudy.com/thesis/thesis-view.asp?key=2601986

[10] H. Lee, S. Jang, M. Wang, A Study on Patients' Perceptions of Patient Safety (Q method), Asia-pacific Journal of Law, Politics and Administration, (2017), Vol.1, No.2, pp.1-6.

[11] M. Wang, S. Jang, A Study on the Subjectivity of Nursing Students on Dating Violence, International Journal of Advanced Nursing Education and Research, (2017), Vol.2, No.1, pp.97-102.

[12] S. Jang, The Subjectivity for Open Adoption of Nursing Students, International Journal of Advanced Nursing Education and Research, (2018), Vol.3, No.1, pp.59-64.

[13] R. C. Tervo, S. Azuma, G. Palmer, P. Redinius, Medical students' attitudes toward persons with disability : A comparative study, Archives of Physical Medicine and Rehabilitation, (2002), Vol.83, No.11, pp.1537-1542, DOI: 10.1053/apmr.2002.34620

[14] J. S. Lee, A study on attitudes toward person with disabilities of college students, Korean Journal of Social Welfare Studies, (2005), Vol. 26, pp.151-176.

[15] K. Kim, Y. Park, B. S. Lee, J. Y. Kim, Comparison of the Attitudes Toward and Contact with Disabled Person among Health Care Professionals, Lay Persons, and Disabled Persons, Korean Academic Society of Rehabilitation Nursing, (2010), Vol.13 No.1, pp.13-22.

[16] B. S. Lee, The Health Care System for the Persons with Disabilities in Developed Countries and Opening of the Health Care Market, Annals of Rehabilitation Medicine, (2004), Vol.28, No.3, pp.195-203. https://www.earm.org/upload/pdf/Jkarm028-03-01.pdf

[17] B. Edwards, D. J. Higgins, N. Zmijewski, The families caring for a person with a disability study and the social lives of carers, Family Matters, (2007), No.76, pp.8-17.

[18] S. T. O'Dwyer, W. Moyle, M. Z. Gembeck, D. D. Leo, Suicidal ideation in family carers of people with dementia: a pilot study, International Journal of Geriatric Psychiatry, (2013), Vol.28, No.11, pp.1182-1188, DOI: 10.1002/gps.3941 
[19] S. Stansfeld, M. Smuk, J. Onwumere, C. Clark, C. Pike, S. McManus, J. Harris, P. Bebbington, Stressors and common mental disorder in informal carers - An analysis of the English adult psychiatric morbidity survey 2007, Social Science \& Medicine, (2014), Vol.120 (November), pp.190-198, DOI: 10.1016/j.socscimed.2014.09.025

[20] J. Dunst, C. Trivette, G. Deal, Enabling and empowering families, Supporting and strengthening families, Cambridge, MA: Brookline Books, (1994) 